\title{
Evaluation of surface contamination with cyclopho- sphamide in the home setting of outpatients on cancer chemotherapy
}

\author{
Michiko Yuki ${ }^{1}$, Kanae Takase $^{1}$, Satoko Sekine ${ }^{2}$, Takashi I shida ${ }^{2}$ \\ 1. School of Nursing, Fukushima Medical University, Fukushima, Japan. 2. School of Medicine, Fukushima Medical \\ University, Fukushima, Japan.
}

Correspondence: Michiko Yuki. Address: School of Nursing, Fukushima Medical University, Fukushima, Japan. Email: yukimck@fmu.ac.jp

Received: June 3, 2014

Accepted: July 27, 2014

Online Published: August 1, 2014

DOI : 10.5430/jnep.v4n10p16

URL: http://dx.doi.org/10.5430/jnep.v4n10p16

\section{Abstract}

Purpose: To monitor the urinary excretion of cyclophosphamide by five patients during the first 48 hours after cyclophosphamide administration and to evaluate surface contamination with cyclophosphamide in the patients' homes via their excreta 48 hours after the completion of chemotherapy.

Methods: Urine samples were taken from five female patients with breast cancer at their homes during the 48 hours after administration of cyclophosphamide. Wipe samples were also collected from their home settings. All samples were analyzed for cyclophosphamide using gas chromatography with mass spectroscopy-mass spectrometry.

Results: Fifty-three urine samples were collected from the five patients during two days after cyclophosphamide treatment. Cyclophosphamide was positive in all urine samples. The quantity of cyclophosphamide excreted in each urine sample ranged from 0.09 to $65.99 \mathrm{mg}$. The urinary excretion of cyclophosphamide accounted for $9 \%-34 \%$ of the dose for four of the patients. Cyclophosphamide was measured at levels of 0.01-8.35 in 17 of the 28 wipe samples from all five patients. The areas contaminated with cyclophosphamide, common to all patients, were the toilet seat $\left(0.04-8.35 \mathrm{ng} / \mathrm{cm}^{2}\right)$ and the toilet floor $\left(0.08-1.53 \mathrm{ng} / \mathrm{cm}^{2}\right)$.

Conclusions: Surface contamination of the home settings of outpatients treated with cyclophosphamide was demonstrated 48 hours after cyclophosphamide administration. Contamination of the home setting with antineoplastic drugs administered to outpatients risks exposure to family members.

\section{Key words}

Antineoplastic drugs, Cyclophosphamide, Biological monitoring, Environmental monitoring

\section{I ntroduction}

Antineoplastic drugs are effective against malignant cells; however, they also affect normal cells, which can lead to toxic adverse effects. Antineoplastic drugs are classified as hazardous drugs that cause adverse health effects. Acute allergic reactions, genotoxicity, reproductive effects and carcinogenicity are adverse health effects caused by exposure to antineoplastic drugs that have been reported ${ }^{[1-12]}$. Healthcare workers such as pharmacists and nurses who prepare and/or 
administer antineoplastic drugs are at risk of occupational exposure to these drugs. Although many reports have described these exposures and measures have been taken to minimize occupational exposure for healthcare workers, most of them were preventive measures and surveys conducted in hospitals ${ }^{[13-17]}$.

The people at exposure risk are not only limited to workers in hospitals, who directly handle antineoplastic drugs. Exposure to antineoplastic drugs occurred during routine nursing tasks and the drug could be detected on patients' bedding and their chair seats ${ }^{[18]}$. Furthermore, a previous study reported that the routes of exposure to antineoplastic drugs in nonhospital environments was investigated ${ }^{[19]}$. The highest exposure levels were detected in industrial laundry facilities due to inhalation by workers dealing with contaminated hospital laundry, as well as due to cleaning toilets and washing treated patients in homecare and nursing home sectors. However, in this study, it was unclear how much time had elapsed since patients received treatment. Moreover, although drug contamination of cleaning cloth and cleaning water was confirmed, the specific location within the house that was contaminated was not identified.

Safe guidelines have been developed to prevent exposure to these drugs ${ }^{[20-23]}$. According to these guidelines, the excreta (e.g., urine, sweat, and feces) of patients who have received anticancer drug treatment may be contaminated with cytotoxic metabolites. It is recommended that patient excreta should be safely handled during the 48 hour period after drug administration. However, the excretion time varies for different types of drugs; therefore, it is important to consider the duration of specific drug excretion profile. Anticancer chemotherapy has shifted from the inpatient (involving an overnight stay in hospital) to the outpatient setting, and the proportion of patients treated as outpatients is increasing. Patients treated with antineoplastic drugs in the outpatient setting spend a lot of time at home, and few investigations have focused on the surface contamination with antineoplastic drugs in the patients' homes via their excreta 48 hours after the completion of chemotherapy ${ }^{[24]}$.

In the present study, we selected patients with breast cancer treated with cyclophosphamide (CPA) (classified by the International Agency for Research on Cancer as a genotoxic carcinogen in humans) in an outpatient setting. The aims of the present study were: (a) to measure the quantity of CPA excreted in urine during the 48-hour period after CPA administration to patients in an outpatient setting and (b) to evaluate surface contamination with cyclophosphamide in the home setting that may have occurred during the 48-hour period following administration via the excreta of patients.

\section{Methods}

\subsection{Patients}

Five Japanese patients with breast cancer who periodically received CPA at the Outpatient Chemotherapy Center of University Hospital A were enrolled. All patients were administered an intravenous bolus dose of cyclophosphamide. A list of patients was as follows:

$$
\begin{aligned}
& \text { Patient 1: } 58 \text { years old, CPA } 753 \mathrm{mg}\left(500 \mathrm{mg} / \mathrm{m}^{2}\right) \\
& \text { Patient 2: } 66 \text { years old, CPA } 700 \mathrm{mg}\left(581 \mathrm{mg} / \mathrm{m}^{2}\right) \\
& \text { Patient 3: } 61 \text { years old, CPA } 712 \mathrm{mg}\left(500 \mathrm{mg} / \mathrm{m}^{2}\right) \\
& \text { Patient 4: } 43 \text { years old, CPA } 796 \mathrm{mg}\left(500 \mathrm{mg} / \mathrm{m}^{2}\right) \\
& \text { Patient 5: } 51 \text { years old, CPA } 800 \mathrm{mg}\left(497 \mathrm{mg} / \mathrm{m}^{2}\right)
\end{aligned}
$$

The performance status was assessed as grade 0 in all patients according to Eastern Cooperative Oncology Group criteria ${ }^{[25]}$. This criteria is popular in Japan. This study was approved by the Ethics Committee of Fukushima Medical University. 


\subsection{Urine sampling (biological monitoring)}

After each patient received a cycle of CPA chemotherapy in the outpatient center, the surveyor visited the home of the patient and explained the test to patients. Patients conducted their urine sample collection during the 48 hours after CPA administration at their home and recorded the time and volume of every urination. Ten milliliters of urine sample were collected each time using a Cyto Urine Kit (Exposure Control Sweden AB, Bohus-Björkö, Sweden). The collected samples were immediately stored in a compact freezer (SC-DF25, TWINBIRD, Japan) solely used for the purpose of storing urine samples, at $-20^{\circ} \mathrm{C}$.

\subsection{Wipe sampling (environmental monitoring)}

Wipe surveys were conducted to detect possible contamination with CPA in the patients' homes during the 48-hours after CPA administration. At the 48-hour time point after CPA treatment, the surveyor revisiting the homes of the patients asked them the following questions:

"How many times did you pass urine at home during the last 48 hours after receiving chemotherapy at the outpatient service?" and "Have you experienced vomiting during the last 48 hours after receiving chemotherapy, and if so, where did you vomit at home and how did you dispose of the vomitus?"

The surveyor identified possible sites of drug contamination based on the responses of the patients. Wipe sampling was conducted in the bathrooms of patients' homes. Depending on the home setting, five to six areas were selected for each patient focusing on the space around the toilet; i.e., the toilet seat, lid of the toilet seat, flush handle, toilet door knob, toilet floor under the seat, control panel for toilet flush, and wash basin lever. Collection of the wipe samples was performed in the following manner. Each target area was measured prior to collecting the wipe samples. For wipe survey, $17 \mathrm{~mL}$ of 0.03 $\mathrm{M} \mathrm{NaOH}$ solution was dripped over the surface of each target area using a Cyto Wipe Kit (Exposure Control Sweden $\mathrm{AB}$ ) to detect CPA. After pouring the solution over the target area, the wipe samples were collected using two pieces of nonwoven cloth to be soaked up the resulting solution. All samples were stored frozen at $-20^{\circ} \mathrm{C}$ after sampling and during transport until sample preparation and analysis.

\subsection{Analysis of the samples}

All samples remained frozen during shipment to Exposure Control Sweden AB for analysis. Urine samples from the patients administered with CPA and wipe samples from surfaces of the home settings were analyzed for the unchanged form of CPA. Five $\mathrm{mL}$ in each urine sample was used for the determination of CPA. The limit of detection of CPA was $0.01 \mathrm{ng} / \mathrm{mL}$ urine. The urine samples were prepared according to standard procedure ${ }^{[26-28]}$.

The wipe samples were prepared by adding a $0.03 \mathrm{M} \mathrm{NaOH}$ solution (total volume: $160 \mathrm{~mL}{ }^{[26-28]}$. After extraction, a part of the extract was further cleaned up according to standard procedures ${ }^{[26-28]}$. The contamination with CPA per square centimeter was calculated by assuming $100 \%$ recovery and wipe efficiency ${ }^{[26-28]}$. The limits of detection of CPA in urine and in wipe sample were $0.01 \mathrm{ng} / \mathrm{mL}$ and $0.10 \mathrm{ng} / \mathrm{mL}$ of extract, respectively ${ }^{[26-28]}$. Each sample was analyzed using gas chromatography with mass spectroscopy-mass spectroscopy. Descriptive analysis was performed.

\section{Results}

\subsection{Urine samples}

A total of 53 urine samples were collected from five patients during the 48-hour period after CPA administration; CPA was detected in all samples (see Figure 1). The number of samples per patient ranged from one to 19, and the amount of CPA excreted in each urine sample ranged from 0.09 to $65.99 \mathrm{mg}$. Peak urinary excretion varied among patients: patient 1 (peak after 32 hours), patient 2 (6 hours), patient 3 (2 hours), and patient 4 (7 hours). The urinary excretion of CPA accounted for $9.4 \%, 23.4 \%, 34.2 \%$, and $19.3 \%$ of the dose for patients 1-4, respectively. Owing to personal circumstances, 
patient 4 was unable to collect all urine samples and patient 5 collected only one urine sample (48 hours after the completion of treatment).

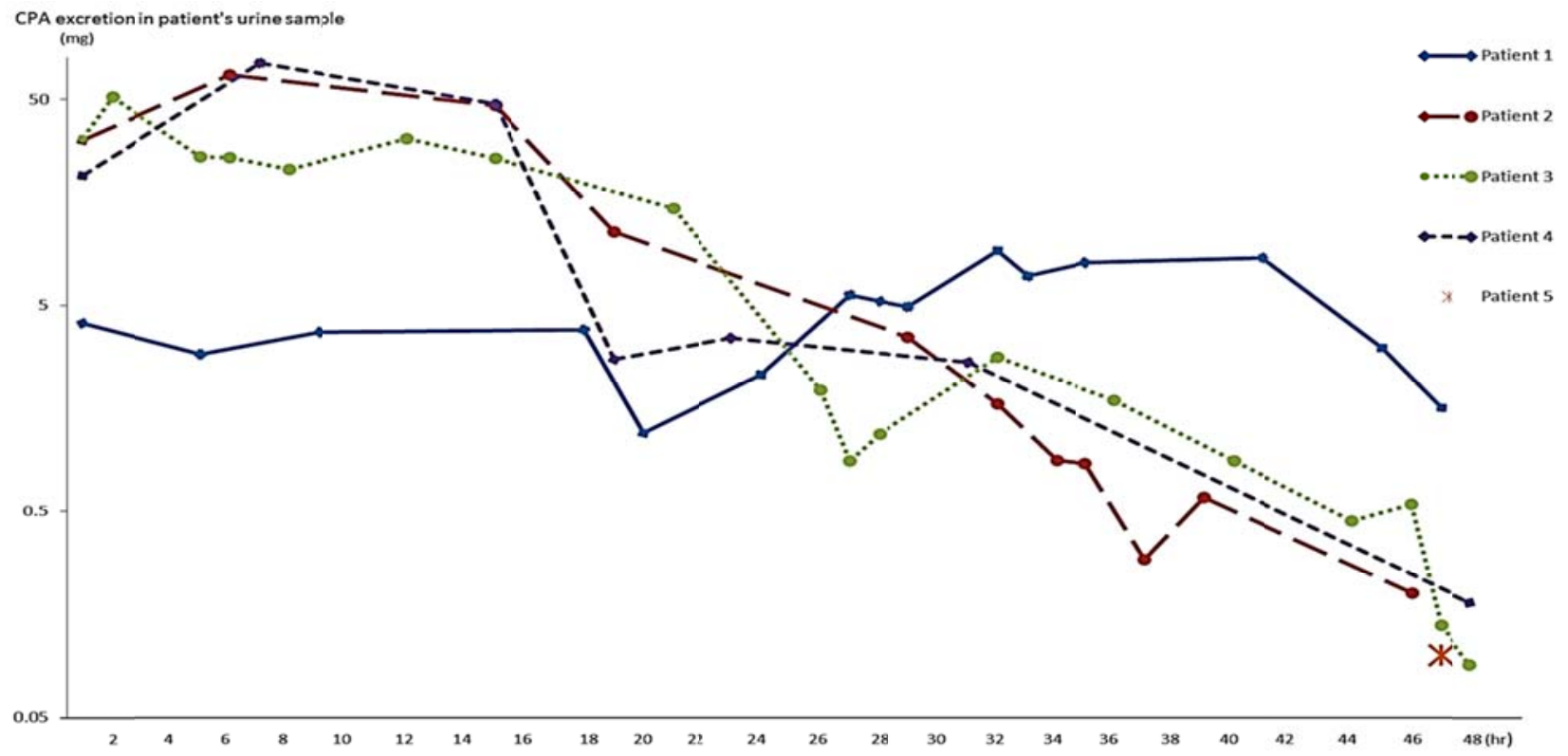

Figure 1. Time-course profiles of CPA excretion in urine samples of patient. CPA: Cyclophosphamide

Table 1. Wipe test results: Surface levels of cyclophosphamide

\begin{tabular}{|c|c|c|c|c|c|}
\hline \multirow{2}{*}{ Patient No. } & \multirow{2}{*}{ Surface description } & \multirow{2}{*}{ Area $\left(\mathrm{cm}^{2}\right)$} & \multicolumn{3}{|l|}{ CPA } \\
\hline & & & (ng/mL NaOH) & (ng) & $\left(\mathrm{ng} / \mathrm{cm}^{2}\right)$ \\
\hline \multirow{5}{*}{1} & Toilet seat & 1225 & 0.75 & 120 & 0.10 \\
\hline & Toilet control panel & 160 & ND & & \\
\hline & Toilet door knob & 384 & 0.24 & 38 & 0.10 \\
\hline & Toilet handrail & 3000 & 0.20 & 32 & 0.01 \\
\hline & Toilet floor & 2700 & 3.64 & 582 & 0.22 \\
\hline \multirow{6}{*}{2} & Toilet seat & 420 & 2.36 & 378 & 0.90 \\
\hline & Lid of toilet seat & 2250 & 0.21 & 34 & 0.01 \\
\hline & Toilet washbasin lever & 70 & ND & & \\
\hline & Toilet door knob & 180 & ND & & \\
\hline & Toilet handrail & 195 & ND & & \\
\hline & Toilet floor & 2000 & 1.02 & 163 & 0.08 \\
\hline \multirow{6}{*}{3} & Toilet seat & 700 & 36.53 & 5845 & 8.35 \\
\hline & Toilet control panel & 1295 & 1.81 & 290 & 0.22 \\
\hline & Toilet flush handle & 81 & 0.28 & 45 & 0.55 \\
\hline & Toilet door knob & 112 & 0.55 & 88 & 0.79 \\
\hline & Toilet washbasin lever & 40 & 0.23 & 37 & 0.92 \\
\hline & Toilet floor & 1350 & 12.88 & 2061 & 1.53 \\
\hline \multirow{6}{*}{4} & Toilet seat & 500 & 0.14 & 22 & 0.04 \\
\hline & Lid of toilet seat & 1350 & ND & & \\
\hline & Toilet washbasin lever & 40 & ND & & \\
\hline & Toilet control panel & 300 & ND & & \\
\hline & Toilet door knob & 24 & ND & & \\
\hline & Toilet floor & 1600 & 1.85 & 296 & 0.19 \\
\hline \multirow{5}{*}{5} & Toilet seat & 1200 & 1.08 & 1.73 & 0.14 \\
\hline & Lid of toilet seat & 1850 & 0.51 & 82 & 0.04 \\
\hline & Toilet door knob & 24 & ND & & \\
\hline & Toilet washbasin lever & 64 & ND & & \\
\hline & Toilet handrail & 240 & ND & & \\
\hline
\end{tabular}

Note. CPA: Cyclophosphamide; ND: Not detected 


\subsection{Wipe samples}

A total of 28 wipe samples were obtained from the five patients; 17 samples were positive for CPA surface contamination (see Table 1). Toilet seats and toilet floor surfaces were the two locations contaminated with CPA for all patients surveyed. The most and least contaminated toilet seats were those of patient $3\left(8.35 \mathrm{ng} / \mathrm{cm}^{2}\right)$ and patient $4\left(0.04 \mathrm{ng} / \mathrm{cm}^{2}\right)$, respectively. The surface contamination of toilet floors ranged from 0.08 to $1.53 \mathrm{ng} / \mathrm{cm}^{2}$. Two out of three samples collected from toilet seat covers were contaminated with CPA: patient $2\left(0.01 \mathrm{ng} / \mathrm{cm}^{2}\right)$ and patient $5\left(0.04 \mathrm{ng} / \mathrm{cm}^{2}\right)$. CPA was also detected in two out of five samples from toilet door knobs, and one out of three samples from the toilet wash basin levers and toilet control panels. None of the patients vomited during the two days after CPA administration.

\section{Discussion}

We examined the amount of CPA excreted in urine during the 48-hour period following outpatient chemotherapy; CPA was detected in all samples. Surface contamination with CPA in the home setting was evident in samples obtained 48 hours after the administration of chemotherapy, which implied that the urinary excretion of CPA continued at least 48 hours after administration. It is known that approximately $13 \%$ of the unchanged form of CPA used to treat patients is excreted in urine following chemotherapy, but the value varies with individual metabolism, ranging from $3 \%$ to $36 \%{ }^{[29]}$. Our findings were consistent with the results by Hedmer et al. ${ }^{[29]}$ : the dose of unchanged CPA ranged from $9 \%$ to $34 \%$ (based on the samples obtained from four of our five patients during the 48-hour period after chemotherapy).

Routes of excretion of CPA include urine, feces, as well as exhaled air, sweat, and breast milk. We conducted wipe surveys to detect surface contamination with CPA in various locations around the toilet focusing on the two routes, which account for the majority of body excretion: urine and feces. The locations contaminated with CPA that were common to all surveyed patients were the toilet seat and toilet floor. In addition, the level of surface contamination in these two locations was highest.

A previous study demonstrated that during home care of patients who recently received chemotherapy in the home setting, no dermal exposure to antineoplastic drugs was detected in healthcare workers who undertook nursing tasks ${ }^{\text {[19] }}$. Residues of antineoplastic drugs were found only on the gloves used by workers during cleaning as well as on cloths and water used for cleaning. They concluded that the risk of contamination of healthcare workers in the home care setting was equal to that for those who work in hospitals. Our findings suggested that not only healthcare workers in hospitals but also family members of the patients are at potential risk of exposure. Furthermore, Yuki, et al. reported that the degree of surface contamination due to CPA 48 hours after the administration of outpatient chemotherapy was equal to or higher than that reported for hospitals in previous studies ${ }^{[24]}$. The levels of contamination were $0.57-7.34 \mathrm{ng} / \mathrm{cm}^{2}$ and $0.03-0.19 \mathrm{ng} / \mathrm{cm}^{2}$ for toilet seats and toilet floors, respectively. In addition, Yuki et al. showed that the family members of the two patients evaluated were also exposed to the drug in the 48-hour period after patients were treated with CPA. Findings of the present study were in accordance with those by Yuki et al., although surface contamination levels were comparable or even higher. These findings suggested that family members of patients are at a high risk of drug exposure.

There is a major difference in contamination by antineoplastic drugs between hospitals and patients' homes. The potential source of exposure at the hospital arises primarily from direct contact with antineoplastic drugs by healthcare workers handling such drugs. Conversely, the source of exposure at home is patients' bodily excretions containing antineoplastic drugs. The drug residues, excreta (urine, feces, vomit, and inhalation) of patients, are exposing family members. It should be noted here that the preparation and/or administration of drugs was not conducted by the patients at home. Therefore, there was no direct contamination in the home setting, e.g., by accidental spills.

It has also been pointed out that there is no correlation between the urinary excretion of CPA as a biomarker of exposure by healthcare workers and the degree of surface contamination in hospitals. The results of the study by Sugiura et al. showed that no healthcare staff were exposed despite the degree of environmental contamination in hospitals, and they explained 
that this was because of several preventive measures that were utilized by individual healthcare staff (e.g., wearing gloves) ${ }^{[30]}$. Similarly, there was no correlation between the amounts of CPA handled and the urinary excretion of CPA ${ }^{[31]}$. Furthermore, a study conducted among 30 hospital pharmacies in the USA in which they showed that surface contamination by antineoplastic drugs significantly decreased if they utilized PhaSeal ${ }^{\circledR}$ closed-system drug transfer devices instead of standard drug preparation techniques during drug preparation ${ }^{[32]}$. These findings suggest that it is possible to minimize occupational exposure to healthcare workers by adopting appropriate engineering controls and using appropriate personal protective equipment (PPE) and handling procedures. Unfortunately, in Japan, the level of understanding among cancer patients concerning protecting their home setting against exposure to antineoplastic drugs is insufficient. Currently, patients and family members usually do not use disposable gloves or gowns when handling excreta, which may include potentially contaminated urine, feces, and vomit. When drug contamination is present in patients' homes where protective measures against contamination are not prioritized, family members of patients undergoing chemotherapy may be at an increased risk of drug exposure. In the present study, surface contamination was detected in the homes of all five patients. The toilet seat and toilet floor surfaces were the two locations in which surface contamination was noted for all patients. For patient 3, all samples were found to be positive for CPA surface contamination (and also highly contaminated).

In our study, we have shown that patients treated with CPA continue to excrete CPA in their urine during the 48-hour period following the completion of chemotherapy and confirmed the presence of surface contamination in the patient's toilet environment. Therefore, suggesting improvements in preventive measures for patients in domestic settings, e.g., flushing the toilet twice is not sufficient. At the very least, guidelines on the handling of potentially contaminated sites and objects (including toilet seats, floors, and door knobs, as well as linen/clothing that may have come in contact with urine and other body fluids of treated patients) are required. Because each cycle of chemotherapy is repeated several times, the family members of patients who share the same living space are also at a risk of repeated exposure to antineoplastic drugs. Furthermore, long-term exposure to low levels of antineoplastic drugs cannot be estimated ${ }^{[33]}$, and its health effects are unknown. These results emphasized the need for implementation of appropriate measures against drug exposure, including patients as well as their family members, and the importance of following protocols.

A limitation of this study is that the sample size was small. In addition, the number of target drug was limited. Further studies should be conducted with a large number of subjects and various kinds of antineoplastic agents to generalize our results.

\section{Conclusions}

Urine samples were collected from five patients during the 48-hour period after receiving CPA chemotherapy. CPA was detected in a continuous manner during these 48 hour in four patients. Only one urine sample was available from patient 5 (48 hours from the completion of treatment) and urine excretion of CPA was also observed in this sample. After urine sampling, wipe surveys were conducted 48 hours after the completion of treatment in the home setting of each patient. Surface contamination with CPA was detected in the toilet environment in all cases. Thus, we can conclude the importance of adopting preventive measures, not only for healthcare workers but also to protect patients' family members from being exposed to antineoplastic drugs.

\section{Funding}

This study was supported by grant from The Secom Science and Technology Foundation.

\section{Conflict of interest}

All authors (Michiko Yuki, Kanae Takase, Satoko Sekine, Takashi Ishida) have declared no conflict of interest. 


\section{References}

[1] Harris CC. Immunosuppressive anticancer drugs in man: their oncogenic potential. Radiology. 1975; 114(1): 163-6. PMid:1108104 http://dx.doi.org/10.1148/114.1.163

[2] Falck K, Grohn P, Sorsa M, Vainio H, Heinonen E, Holsti LR. Mutagenicity in urine of nurses handling cytostatic drugs. Lancet. 1979; 1(8128): 1250-1. http://dx.doi.org/10.1016/S0140-6736(79)91939-1

[3] Fairchild WV, Spence C, Solomon H, MP. G. The incidence of bladder cancer after cyclophosphamide therapy. J Urol. 1979; 122(2): 163-4. PMid:459006

[4] Maguire LC, Dick FR, Sherman BM. The effects of anti-leukemic therapy on gonadal histology in adult males. Cancer. 1981; 48(9): 1967-71. http://dx.doi.org/10.1002/1097-0142(19811101)48:9<1967::AID-CNCR2820480910>3.0.CO;2-0

[5] Hoffman DM. Reproductive risks associated with exposure to antineoplastic agents: a review of the literature. Hosp Pharm. 1986; 21(10): 930-2, 6, 40.

[6] Skov T, Lynge E, Maarup B, Olsen J RM, Winthereik H. Risks for physicians handling antineoplastic drugs. Lancet. 1990; 336(8728): 1446. http://dx.doi.org/10.1016/0140-6736(90)93148-I

[7] Valanis BG, Vollmer WM, Labuhn KT, Glass AG. Association of antineoplastic drug handling with acute adverse effects in pharmacy personnel. Am J Hosp Pharm. 1993; 50(3): 455-62. PMid:8442461

[8] Walusiak J, Wittczak T, Ruta U, Palczynski C. Occupational asthma due to mitoxantrone. Allergy. 2002; 57(5): 461. PMid:11972492 http://dx.doi.org/10.1034/j.1398-9995.2002.13455.x

[9] Kusnetz E, Condon M. Acute effects from occupational exposure to antineoplastic drugs in a para-professional health care worker. Am J Ind Med. 2003; 44(1): 107-9. PMid:12822142 http://dx.doi.org/10.1002/ajim.10230

[10] Cardonick E, Iacobucci A. Use of chemotherapy during human pregnancy. The lancet oncology. 2004; 5(5): $283-91$. http://dx.doi.org/10.1016/S1470-2045(04)01466-4

[11] McDiarmid MA, Oliver MS, Roth TS, Rogers B EC. Chromosome 5 and 7 abnormalities in oncology personnel handling anticancer drugs. J Occup Environ Med. 2010; 52(10): 1028-34. PMid:20881619

[12] IARC. IARC monographic on the evaluation of the carcinogenic risk: the IARC monographs. 2013; 1-109.

[13] Sorsa M, Anderson D. Monitoring of occupational exposure to cytostatic anticancer agents. Mutat. 1996; 355(1-2): $253-61$. http://dx.doi.org/10.1016/0027-5107(96)00031-0

[14] Sessink PJM, Rolf M-AE, Ryden NS. Evaluation of the PhaSeal Hazardous Drug Containment System. Hosp Pharm. 1999; 34(11): 1311-7.

[15] Yoshida J, Kosaka H, Tomioka K, Kumagai S. Genotoxic risks to nurses from contamination of the work environment with antineoplastic drugs in Japan. J Occup Health. 2006; 48(6): 517-22. PMid:17179646 http://dx.doi.org/10.1539/joh.48.517

[16] Nyman H, Jorgenson J, Slawson MH. Workplace contamination with antineoplastic agents in a new cancer hospital using a closed-system drug transfer device. Hosp Pharm. 2007; 42(3): 219-25. http://dx.doi.org/10.1310/hpj4203-219

[17] Connor TH, DeBord DG, Pretty JR, Oliver MS, Roth TS, Lees PS, et al. Evaluation of antineoplastic drug exposure of health care workers at three university-based US cancer centers. J Occup Environ Med. 2010; 52(10): 1019-27. PMid:20881620 http://dx.doi.org/10.1097/JOM.0b013e3181f72b63

[18] Fransman W, Vermeulen R, Kromhout H. Dermal exposure to cyclophosphamide in hospitals during preparation, nursing and cleaning activities. Int Arch Occup Environ Health. 2005; 78(5): 403-12. PMid:15887018 http://dx.doi.org/10.1007/s00420-004-0595-1

[19] Meijster T, Fransman W, Veldhof R, Kromhout H. Exposure to antineoplastic drugs outside the hospital environment. Ann Occup Hyg. 2006; 50(7): 657-64. PMid:16679337 http://dx.doi.org/10.1093/annhyg/mel023

[20] OSHA. OSHA technical manual. Controlling occupational exposure to hazardous drugs. Occupational Safety and Health Administration. 1995; Section VI, Chapter 2.

[21] NIOSH Alert. Preventing occupational exposures to antineoplastic and other hazardous drugs in the health care setting: U. S. Department of Health and Human Services, Cincinnati. 2004; 15-19.

[22] American Society of Health-system Pharmacists. ASHP guidelines on handling hazardous drugs. Journal of Hospital Pharmacy.2006; 63: 1172-1091.

[23] Polovich M. Safe handling of hazardous drugs (2nd ed.). Oncology Nursing Society Pittsburgh, PA: 2011.

[24] Yuki M, Sekine S, Takase K, Ishida T, Sessink PJ. Exposure of family members to antineoplastic drugs via excreta of treated cancer patients. Journal of oncology pharmacy practice: official publication of the International Society of Oncology Pharmacy Practitioners. 2013; 19(3): 208-17. PMid:23060485 http://dx.doi.org/10.1177/1078155212459667

[25] Oken MM, Creech RH, Tormey DC, Horton J, Davis TE, ET. M, et al. Toxicity and response criteria of the Eastern Cooperative Oncology Group. Am J Clin Oncol. 1982; 5(6): 649-55. PMid:7165009 http://dx.doi.org/10.1097/00000421-198212000-00014 
[26] Sessink PJ, Boer KA, Scheefhals AP, Anzion RB, RP. B. Occupational exposure to antineoplastic agents at several departments in a hospital. Environmental contamination and excretion of cyclophosphamide and ifosfamide in urine of exposed workers. Int Arch Occup Environ Health. 1992; 64(2): 105-12. PMid:1399019 http://dx.doi.org/10.1007/BF00381477

[27] Sessink PJ, Anzion RB, Van den Broek PH, RP. B. Detection of contamination with antineoplastic agents in a hospital pharmacy department. Pharm Weekbl Sci. 1992; 14(1): 16-22. PMid:1553250 http://dx.doi.org/10.1007/BF01989220

[28] Sessink PJ, Scholtes MM, Anzion RB, RP. B. Determination of cyclophosphamide in urine by gas chromatography-mass spectrometry. J Chromatogr. 1993; 616(2): 333-7. http://dx.doi.org/10.1016/0378-4347(93)80404-R

[29] Hedmer M, Tinnerberg H, Axmon A, Jonsson BA. Environmental and biological monitoring of antineoplastic drugs in four workplaces in a Swedish hospital. Int Arch Occup Environ Health. 2008; 81(7): 899-911. PMid:18066576 http://dx.doi.org/10.1007/s00420-007-0284-y

[30] Sugiura S, Nakanishi H, Asano M, Hashida T, Tanimura M, Hama T, et al. Multicenter study for environmental and biological monitoring of occupational exposure to cyclophosphamide in Japan. Journal of oncology pharmacy practice: official publication of the International Society of Oncology Pharmacy Practitioners. 2011; 17(1): 20-8. PMid:20472603 http://dx.doi.org/10.1177/1078155210369851

[31] Favier B, Gilles L, Desage M, Latour JF. [Analysis of cyclophosphamide in the urine of antineoplastic drugs handlers]. Bull Cancer. 2003; 90(10): 905-9. PMid:14706919

[32] Sessink PJ, Trahan J, Coyne JW. Reduction in Surface Contamination With Cyclophosphamide in 30 US Hospital Pharmacies Following Implementation of a Closed-System Drug Transfer Device. Hosp Pharm. 2013; 48(3): 204-12. PMid:24421463 http://dx.doi.org/10.1310/hpj4803-204

[33] Davis J, McLauchlan R, Connor TH. Exposure to hazardous drugs in healthcare: an issue that will not go away. Journal of oncology pharmacy practice: official publication of the International Society of Oncology Pharmacy Practitioners. 2011; 17(1): 9-13. PMid:21372152 http://dx.doi.org/10.1177/1078155210388462 